\title{
Evaluation of the representative elementary volume (REV) of a fractured geothermal sandstone reservoir
}

\author{
Christian Müller • Siegfried Siegesmund • \\ Philipp Blum
}

Received: 27 May 2009/Accepted: 2 February 2010/Published online: 2 March 2010

(C) The Author(s) 2010. This article is published with open access at Springerlink.com

\begin{abstract}
The objective of this study is to evaluate a representative elementary volume (REV) in a fractured geothermal sandstone reservoir in Germany using the discrete fracture network (DFN) model approach. Due to the lack of in situ data from the deep geothermal reservoir, field measurements of outcrop reservoir analogues were conducted to get a quantitative description of the DFN. Field measurements reveal that the geometry of the DFN is largely influenced by the lithological layering (e.g. relationship between joint spacing and bed thickness). Thus, DFN models have to be completed individually for each layer since each bed is distinct compared to its neighbouring beds. Various DFNs were generated using statistical-derived fracture input data. The two-dimensional universal distinct element code UDEC was used for fracture flow simulations. In order to determine the minimum $\mathrm{REV}$, the equivalent average conductivity tensors were obtained with increasing block size. Plots of conductivity tensor coefficients versus block size exhibit only minor variation of the hydraulic properties with increasing block size. Hence, an REV size of $10 \mathrm{~m} \times 10 \mathrm{~m}$ could be determined for all studied stochastically derived discrete fracture networks.
\end{abstract}

C. Müller $(\bowtie) \cdot S$. Siegesmund

Geoscience Centre, University of Göttingen,

Goldschmidtstraße 3, 37077 Göttingen, Germany

e-mail: christian.mueller@geo.uni-goettingen.de;

cmuelle@gwdg.de

P. Blum

Center for Applied Geoscience (ZAG), University of Tübingen,

Sigwartstrasse 10, 72076 Tübingen, Germany
Keywords Geothermal energy - Numerical methods . Discrete fracture network - Fracture flow - Sedimentary rocks - Universal distinct element code UDEC . Buntsandstein

\section{Introduction}

Investigation of paths for fluid flow in rocks plays a major role in many branches of earth sciences and engineering, e.g. hydrogeology, petroleum geology or waste management. In the view of decreasing energy resources, the discussion about climate change and a fast-growing world population, there is an increasing interest in the use of geothermal heat potential of rocks at depth. The use of geothermal energy has a long tradition in countries with active volcanism (Bertani 2005). There are also remarkable geothermal resources in Germany, even though the temperature is rather moderate in the subsurface (Jung 2007). One of the main difficulties in the use of geothermal energy is the unpredictable hydraulic conductivity in the geothermal reservoir. In many areas of Germany, sedimentary rocks are common at depths interesting for geothermal energy. Due to their tectonic history, faults and fractures are common throughout these sedimentary rocks. Fractures not only improve the hydraulic conductivity of many reservoirs, but also induce significant permeability anisotropy due to the geometry of the discrete fracture network. Thus, knowledge about the fracture system is a major concern for predicting the anisotropy of the hydraulic conductivity in a geothermal reservoir. Such knowledge helps to minimise the risk and thereby increases the economic potential of geothermal energy.

Unlike in situ tests that are in many cases difficult and expensive, numerical methods provide a priori a very powerful approach for investigating the hydraulic 
conductivity of a fractured reservoir. For an economic use of geothermal energy, the distance between the boreholes in geothermal doublet operation must exceed 1,000 m (Jung 2007). Therefore, hydraulic simulations in the farfield (decametre-scale) are required. However, due to the complexity of processes occurring in the natural system, hydraulic models for far-field problems are not generally composed of individual fractures. For such cases, the equivalent porous medium (EPM) approach is widely used (e.g. Long et al. 1982; Khaleel 1989; Lee et al. 1995; Min et al. 2004; Blum et al. 2005, 2009). This conceptual model implies that fluid flow is similar to that through porous media having equivalent hydraulic properties as a given network with fractures explicitly represented. The evaluation of equivalent hydraulic properties generally assumes the concept of the representative elementary volume (REV, Bear 1972). The REV of a fractured rock mass is the smallest volume over which the studied parameter, in this case the hydraulic conductivity, yields a constant value (Long et al. 1982; Shapiro and Andersson 1983; Blum et al. 2007). One particular issue of concern is the evaluation of the REV in fractured rock masses, due to the fact that fluid flow in fractured rock masses is highly scale-dependent (Bear 1972; Long et al. 1982; Lee et al. 1995; Min et al. 2004; Blum et al. 2005, 2007; Baghbanan and Jing 2007). There is no guarantee that an REV exists in a specific rock mass since fluid flow is largely influenced by the complexity and heterogeneity of the fracture system (Neuman 1987; Kulatilake and Panda 2000). Although there are many studies showing the important role of fractures on fluid flow, only few detailed studies consider the complexity and heterogeneity of fracture systems in Germany (e.g. Dietrich et al. 2005; Kohl and Megel 2007).

The objective of this study is the evaluation of an REV in a fractured sedimentary rock mass in Germany using the approach of discrete fracture network (DFN) models. DFN analysis is a widely applied modelling approach, where the fluid flow is dominated by the fractures and the matrix permeability is to be negligible (Sahimi 1995; Adler and Thovert 1999; Jing 2003; Zhang and Sanderson 2002; Dietrich et al. 2005). The main advantage is a detailed definition of the fracture geometry and, therefore, a realistic representation of the natural system. Since fracture systems are geometrically complex, DFN models are usually generated using statistical input data of fracture systems (e.g. Long 1983; Priest and Samaniego 1983; Min et al. 2004; Blum et al. 2005, 2007; Hitchmough et al. 2007; Lee et al. 2007). Therefore, the primary requirement is a detailed description of the characteristics and geometries of the fracture systems (e.g. fracture orientation, fracture length, fracture spacing and effective hydraulic aperture; e.g. Priest 1993; Lee and Farmer 1993). Due to the lack of in situ data from the deep geothermal reservoir, field measurements of outcrop reservoir analogues were conducted to get a quantitative description of the DFN that occurs in the studied fractured sandstone.

\section{Materials and methods}

\section{Geological setting}

The field measurements were performed in Lower Saxony, North Germany (Fig. 1). The studied rock formations belong to the Solling Formation and are part of the Triassic Middle Buntsandstein, a sandstone interval occurring in the North German Basin (Bachmann 1998; Lepper and Röhling 1998). Investigations of geothermal energy in the same Triassic sandstones are being conducted in a pilot drill hole in Northern Germany maintained by the Federal Institute for Geosciences and Natural Resources (Kehrer et al. 2007).

The studied area is located between the Weser river region and the Eichsfeld region near Göttingen, at the southern margin to the playa facies of the North German Basin. It comprises rocks of the Solling Formation deposited on a paleohigh and-low position that are the Eichsfeld-Altmark Swell and the Reinhardswald Trough, respectively (Fig. 1b). The development of several NNE trending paleo-swells and paleo-lows during Triassic was the result of thermal subsidence and an increase of tectonic instability (Lepper and Röhling 1998). As opposed to the swells, where little sedimentation with hiatus dominates, the troughs are characterised by complete stratigraphic record and a great accumulation of sediments (Weber and Ricken 2005). These paleogeographic structures are not only restricted to the margins of the basin, but occur in central parts as well (Lepper and Röhling 1998). The general thickness of the Solling Formation in the Reinhardswald Trough varies by about $100 \mathrm{~m}$, whereas the Eichsfeld-Altmark Swell shows a distinct decrease in thickness down to 10 m (Bindig 1991; Rettig 1996).

The investigated area provides numerous outcrops since the sandstones have been quarried as a natural building stone in the past and to this present day. Several outcrops located at the centre and the northern part of the Reinhardswald Trough, as well as at western flank of the Eichsfeld-Altmark Swell, were investigated to discern possible regional distinctions in the fracture systems between these paleogeographic structures (Fig. 1b). The investigated Solling Formation of the German Buntsandstein is normally characterised by an alternation of flat-bedded sandstones, intercalated with silt- or claystones. Field measurements were restricted to representative outcrops. Because of their fluvial architecture, the sandstones are not constant in thickness and thinned out (decametres in width) away from the axis parts of channel systems. 
Fig. 1 Illustration of a the paleogeography of the German Basin in Lower Triassic (modified after GDNRW 2003) and $\mathbf{b}$ isopach map of the Solling Formation in the Reinhardswald Trough and the Eichsfeld-Altmark Swell (EAS; modified after Weber and Ricken 2005)

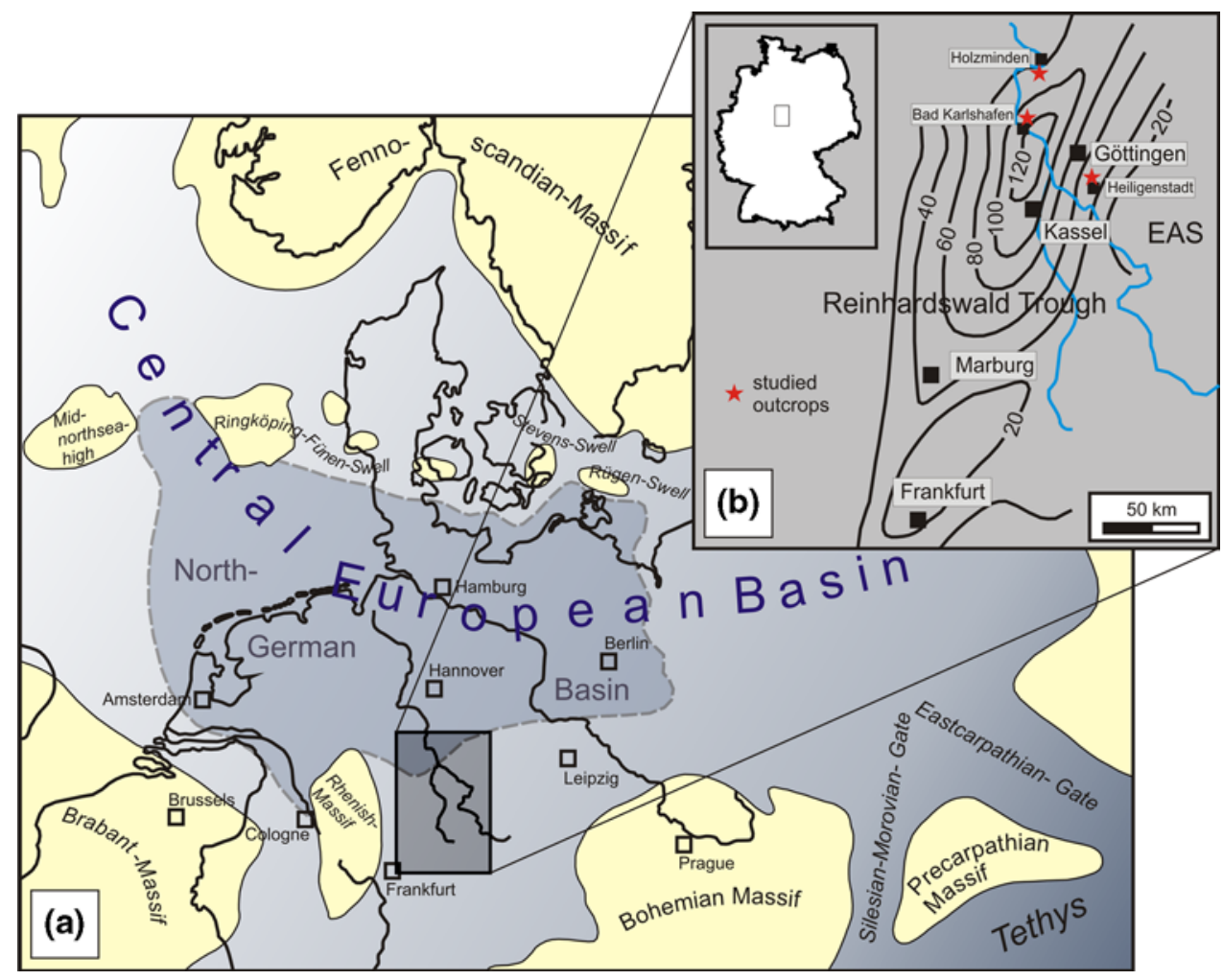

\section{Methodology}

In order to obtain the REV of the studied fractured sandstone, the methodology comprises three main stages. The first stage comprises the analysis of the fracture network since the hydraulic behaviour strongly depends on its geometry. Intensive field measurements of outcrop reservoir analogues were performed and a detailed description of the fracture system is given by various fracture parameters. Fractures described here are joints that are, according to Cloos (1936), tension fractures without shear displacement. The second stage gives a conceptual model of the fracture system. Furthermore, statistical-derived fracture input data (carried out from field measurements in the first stage) and the distinct element code UDEC were used to generate various discrete fracture networks. The third stage comprises numerical simulations of the discrete fracture network using UDEC. The objective of the two-dimensional (2D) fracture flow simulations was the determination of the effective hydraulic conductivity tensors and the evaluation of the representative elementary volume (REV) of the studied rock formations.

\section{Fracture network analysis}

The drawback of field measurements is the uncertainty whether the fracture system in the subsurface is similar to those detected in the fractured outcrop. A study by Nirex
(1997), however, could demonstrate that the observed fracture densities on surface exposures can be compared reasonably well with those determined from deep borehole data. Nevertheless, the fracture system of rocks varies according to the processes that have taken place after deposition (subsidence, diagenesis, uplift and erosional unloading). Hence, such fracture systems are not universal and must be explicitly assessed for each site. However, field measurements of outcrop reservoir analogues can contribute to basic knowledge of the fracture system in sedimentary rocks (e.g. Nirex 1997). The investigated data can complement other approaches (e.g. information from seismic data or borehole image $\operatorname{logs}$ ) that exhibit only limited data on the fracture system in the considered geothermal reservoir.

Priest (1993) provides a detailed summary of the description and the sampling of discontinuities for rock engineering. Sampling bias is introduced when measuring fracture parameters. Hence, the field derived data should be corrected (e.g. Terzaghi 1965; Wathugala et al. 1990). In addition to orientation parameters, a fracture system is generally described by the length and spacing of individual joints (Huang and Angelier 1989). Methods for the measurement of fracture orientation are described by several authors (e.g. Lee and Farmer 1993; Priest 1993). Fracture orientation is usually determined both in outcrops with a compass and from boreholes or cores (Narr 1996; Wu and Pollard 2002). A technique that allows fracture orientation 
measurements by means of stereographic image analysis is presented in Grobler et al. (2003).

To collect data about fracture orientation, traces of the dip direction and the dip angle, of several hundred joint surfaces were measured with a compass on vertical outcrop walls. Joints that are orientated parallel to the quarry walls are commonly underestimated. Since the cutting of the rocks is controlled by the fracture system, the quarry walls are usually oriented parallel to each fracture sets. Thus, the fracture set could be measured in two directions, and for this reason correction for sampling bias was not needed in the current study.

Unlike intrusive igneous rocks, where no uniform distribution generally exists, many studies show that joint spacing in sedimentary rocks tends to be regular (Pollard and Aydin 1988). In addition to mechanical properties and tectonic stress, the spacing of joints is largely influenced by the thickness of the layer. The majority of research reveals that fracture spacing is roughly proportional to the thickness of the layer (Huang and Angelier 1989; Narr and Suppe 1991; Gross 1993; Gross et al. 1995; Wu and Pollard 1995; Ji and Saruwatari 1998). The fracture spacing can be directly measured from cores, boreholes or outcrops. In this study fracture spacing was measured at each location as the distance between the fractures along a line perpendicular to the average orientation of both fracture sets (Narr and Suppe 1991; Gross 1993; Bai and Pollard 2000). The relationship between layer thickness and fracture spacing was studied by placing line samples on various layers within different thicknesses, but each with constant thickness along the scan line. Because of their fluvial architecture, the sandstones are not constant in thickness and slight variations in thickness along the scan line could not be avoided. Thus, an average layer thickness was calculated from a number of measurements along the scan line.

Measuring the trace length of discontinuities is rather complicated since the entire joint areas are rarely observable due to limited exposures. Fracture trace length can be measured in several ways such as scanlines, trace maps and/or aerial photographs (e.g. Pahl 1981; Kulatilake and Wu 1984; Mauldon 1998; Zhang and Einstein 1998; Song and Lee 2001). The observed fracture trace lengths also need to be corrected for sampling bias (e.g. Priest and Hudson 1981; Pickering et al. 1995). For this study, the fracture lengths were obtained from two-dimensional outcrop trace mappings.

Fracture network generation

Fracture network models generated here are two-dimensional (2D), due to the nature of observation in the field. Compared to three-dimensional (3D) models, which are in many cases difficult to handle, but give a more realistic description of the natural system, 2D fracture network models are commonly used for hydraulic simulations (e.g. Kolditz 1995a, b). Fracture network models were generated using the commercial distinct element code UDEC (Itasca 2006). UDEC contains a statistical joint generator, which is based on geometric properties of rock discontinuities, described in terms of statistical parameters. The generation is characterised by eight generation parameters: four of these control mean geometric properties, and four control the standard deviation of random fluctuation about the mean (Fig. 2).

Hydraulic modelling and REV analysis

The aim of the hydraulic analysis is to determine the average components of the conductivity tensors and the minimum size to approximate a representative elementary volume (REV). In order to study the hydraulic behaviour of the fractured sandstones, numerical simulations of the DFN were performed using UDEC (Itasca 2006). Flow calculations are based on the cubic law for hydraulic resistance versus fracture aperture, as given by Snow (1965). The cubic law assumes laminar, two-dimensional flow between two infinite planar parallel plates with constant hydraulic aperture. Because of the major assumptions that the cubic law incorporates, the validity and the application of the law to natural non-parallel rough fractures has often been questioned and discussed (e.g. Witherspoon et al. 1980; Thompson and Brown 1991; Renshaw 1995; Berkowitz 2002). Nevertheless, the model appears to be valid for fractures with rough surfaces when only minor fracture aperture changes occur along the flow direction (e.g.

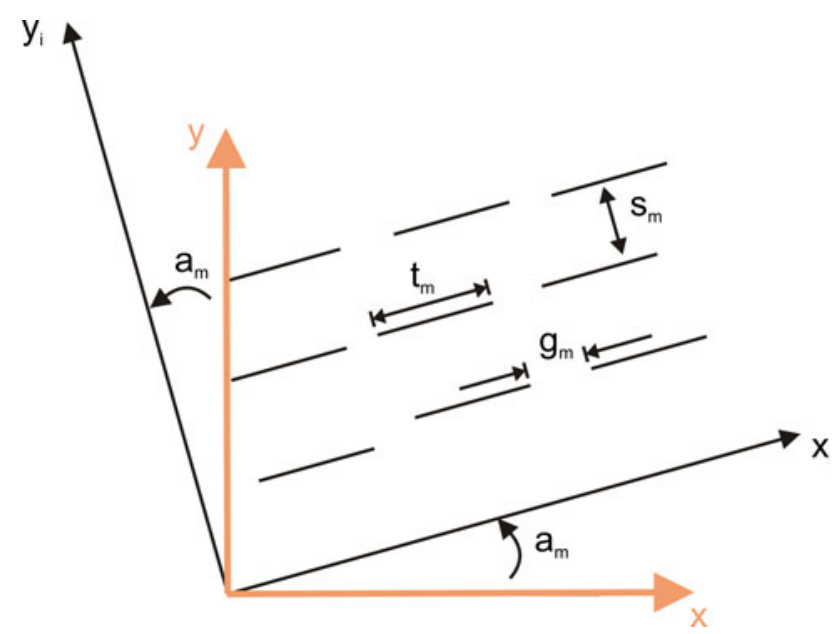

Fig. 2 The parameters given with the JSET joint generator in UDEC after Itasca (2006) are: the angle of joints to the x-axis $\left(a_{\mathrm{m}}\right)$, trace length of joints $\left(t_{\mathrm{m}}\right)$, joint spacing normal to joints $\left(s_{\mathrm{m}}\right)$, gap length between joint segments $\left(g_{\mathrm{m}}\right)$ as well as their standard deviation $\left(a_{\mathrm{d}}, t_{\mathrm{d}}\right.$, $s_{\mathrm{d}}$ and $\left.g_{\mathrm{d}}\right)$ 
Brown 1987; Moreno et al. 1988). Since both aperture distributions from field measurements and hydraulic aperture data from hydraulic test were not gathered, a constant hydraulic aperture of $200 \mu \mathrm{m}$ was used in the current study, which is in a similar range of previously observed apertures in other sandstone formations (e.g. Steele et al. 2006; Hitchmough et al. 2007). However, an arbitrary constant hydraulic aperture can be applied on the acceptance of the cubic law by a scale function described in Blum et al. (2007). For the flow simulations, a constant water density of $1,000 \mathrm{~kg} / \mathrm{m}^{3}$, gravity acceleration of $9.81 \mathrm{~m} / \mathrm{s}^{2}$ and a dynamic viscosity of $0.001 \mathrm{~kg} / \mathrm{ms}$ are assumed.

When determining equivalent hydraulic properties of fractured rocks for large scale modelling the conductivity tensor is a key parameter. Several methods have been used formerly by researchers to evaluate the components of the 2D hydraulic conductivity tensor (e.g. Long et al. 1982; Panda and Kulatilake 1999). In the current study, the evaluation was based on the study by Jackson et al. (2000) and Blum et al. (2005), who simulated flow through a fractured block using several head directions with a uniform head gradient as a hydraulic boundary condition. A rotation of the head gradient from $0^{\circ}$ to $150^{\circ}$ in $30^{\circ}$ steps provides different flow results from which equivalent hydraulic conductivities can be determined.

Assuming Darcian flow, three hydraulic conductivity tensor components, $k_{\mathrm{xx}}, k_{\mathrm{yy}}$ and $k_{\mathrm{xy}}$, were estimated by minimising the following expression (Blum et al. 2005):

$$
\begin{aligned}
& \sum_{i-1}^{6}\left[\left(q_{\mathrm{x}}\right)_{i}+\left(k_{\mathrm{xx}} \cos \varphi_{i}+k_{\mathrm{xy}} \sin \varphi_{i}\right)\right]^{2} \\
& +\left[\left(q_{\mathrm{y}}\right)_{i}+\left(k_{\mathrm{xy}} \cos \varphi_{i}+k_{\mathrm{yy}} \sin \varphi_{i}\right)\right]^{2}
\end{aligned}
$$

where $\varphi_{i}$ is the direction of the hydraulic gradient. The principal conductivity tensors $k_{\max }$ and $k_{\min }$ and the principal direction (angle between $k_{\max }$ and $\mathrm{x}$-axis; anticlockwise) can be obtained using following equation (Blum et al. 2007):

$$
\begin{aligned}
& k_{\max }=\frac{k_{\mathrm{xx}}+k_{\mathrm{yy}}+\sqrt{\left(k_{\mathrm{xx}}+k_{\mathrm{yy}}\right)^{2}-4\left(k_{\mathrm{xx}} k_{\mathrm{yy}}-k_{\mathrm{xy}}^{2}\right)}}{2} \\
& k_{\min }=\frac{k_{\mathrm{xx}}+k_{\mathrm{yy}}-\sqrt{\left(k_{\mathrm{xx}}+k_{\mathrm{yy}}\right)^{2}-4\left(k_{\mathrm{xx}} k_{\mathrm{yy}}-k_{\mathrm{xy}}^{2}\right)}}{2} \\
& \theta_{\max }=\tan ^{-1}\left(\frac{k_{\max }-k_{\mathrm{xx}}}{k_{\mathrm{xy}}}\right)
\end{aligned}
$$

To simplify matters, a unit head gradient was employed $(9.810 \mathrm{~Pa} / \mathrm{m})$. To determine the minimum size required to approximate the REV, the equivalent average conductivity tensors were obtained at increasing block sizes.

\section{Results and discussion}

Fracture network analysis

In order to give a detailed description of the geometry of the fracture system, three parameters are selected: (1) fracture orientation, (2) fracture spacing, and (3) fracture length.

\section{Fracture orientation}

The orientations of more than 1,500 fractures from the investigated outcrops are plotted on stereo nets as normals to joint plane (Fig. 3). Furthermore, the mean and standard deviation were determined from the orientation data. Field observations indicate a fracture network made up of vertical joints that are orientated perpendicular to bedding plane. Vertical joints are exhibited as two orthogonal joint sets, namely a north-south striking (set I) and an east-west striking set (set II). In contrast to fracture set I, joints of fracture set II are less consistent in strike direction, and show a higher scattering in strike and dip. Differences in orientation between the studied sites are probably the result of differences in the regional stress regime or displacement of layers by diapirism of the underlying Zechstein salt.

\section{Fracture spacing}

Plots of bed thickness versus median joint spacing for each investigated site demonstrate that fracture spacing is roughly proportional to the thickness of the layer (Fig. 4). The median is a better and more stable estimator of average joint spacing than the arithmetic mean (Narr and Suppe 1991). The slope of the median joint spacing versus layer thickness regression line, generally referred to as the coefficient of joint spacing $k$ (Ladeira and Price 1981), ranges between 0.71 and 1.39 for the studied outcrops. $k$ values for different sandstones reported in the literature vary from 0.60 to 1.27 (Ji and Saruwatari 1998). The centre of the Reinhardswald Trough shows the lowest $k$ values of the studied sites. Furthermore, there is a difference in fracture spacing between the fracture sets of one site. The joint spacing for the north-south joint set is less than for the east-west joint set, indicating that the north-south joint set has a greater fracture density than the east-west joint set (Fig. 4a). However, a similar relationship between spacing and layer thickness cannot be observed at the swell site. The sandstones at this site comprise thicker sandstone layers, with joints so widely spaced that the fracture spacing could only be measured just along a few line samples (Fig. 4c). Due to lack of data, a reliable analysis could not be conducted for this site, although it is well exposed. 

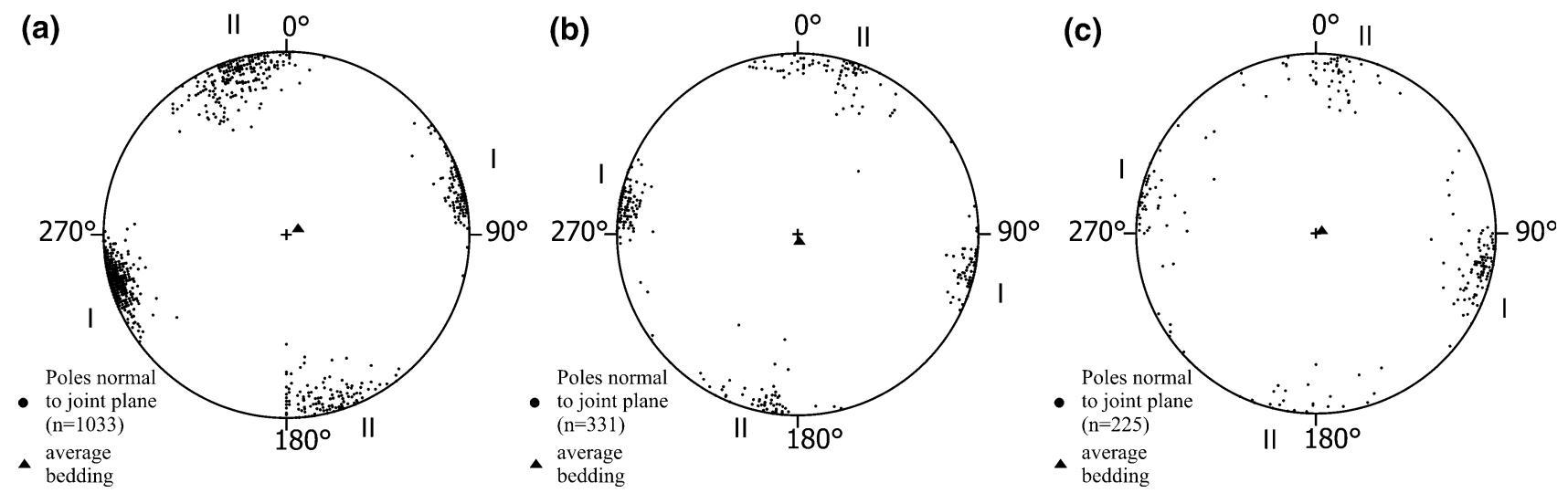

Fig. 3 Poles normal to joint plane on the Schmidt net (equal area projection, lower hemisphere) from all investigated sites, a centre of the Reinhardswald Trough, b northern part of the Reinhardswald Trough and $\mathbf{c}$ the Eichsfeld-Altmark Swell
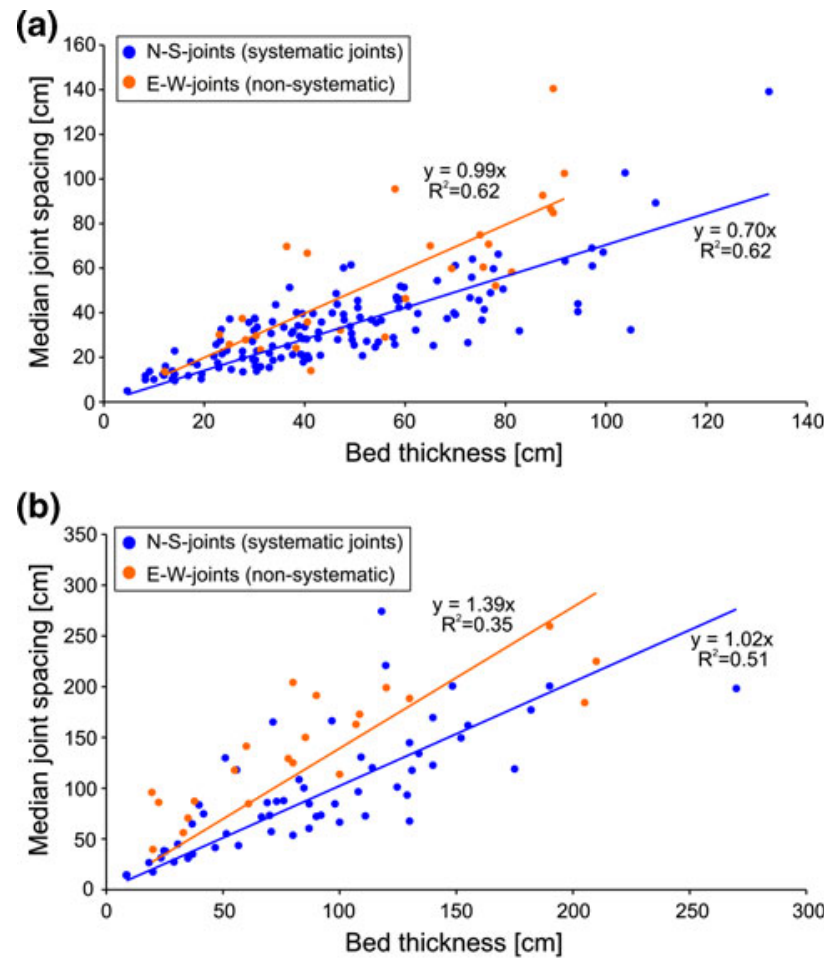

(c)

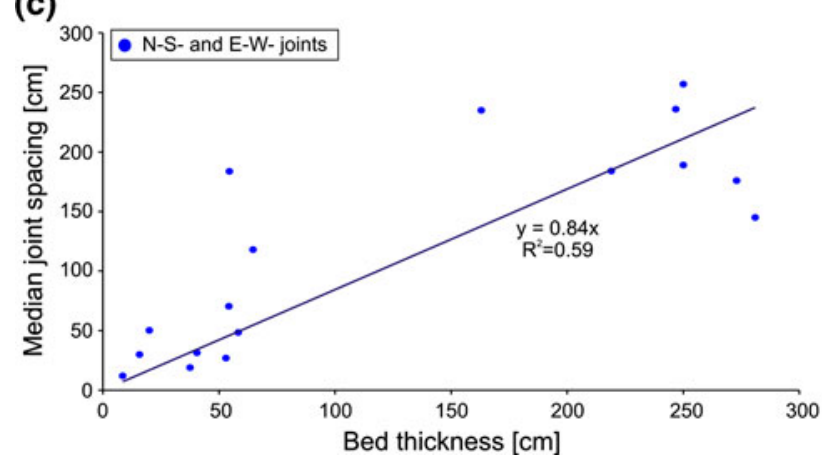

Fig. 4 Bed thickness versus median fracture spacing for each investigated site, a Reinhardswald Trough, b northern part of the Reinhardswald Trough and $\mathbf{c}$ the Eichsfeld-Altmark Swell

\section{Fracture length}

In this study, the fracture lengths were obtained from twodimensional outcrop trace mappings. An important characteristic is the different fracture length of the two joint sets. Fractures of the north-south striking joint set (set I) are more continuous in length and their traces usually terminate within the host rock. In the vertical to bedding plane view, they frequently cut across many beds. In contrast, the joints of the east-west joint set (set II) are more discontinuous and less consistent in strike direction and dip angle. They never cross and commonly abut with T-intersections against other joints, which typically resembles a ladder-like pattern on the bedding plane surface. Hence, measurements focus on fracture length of joint set I since cross joints are limited in length by the intervening distance between joint set I. Only one quarry in the centre of the Reinhardswald Trough was suitable for measuring trace length. Furthermore, trace mappings could only be applied on vertical quarry walls due to the fact that no suitable horizontal exposure could be found for reliable fracture length analysis. Usually, the trace length data fit a log-normal or exponential distribution (e.g. Baecher et al. 1977; Lee and Farmer 1993). In the current study, the trace length distribution was found to be close to log-normal (Fig. 5).

In order to derive the mean trace length of the distribution, the method of Pahl (1981) was used, which considers sampling bias. Pahl (1981) classified the joints in the sampling window into three types, depending on whether they intersect, transect or contain the joint trace. Dividing the joints into these categories and substituting these values to Pahl's equation (Pahl 1981; Lee and Farmer 1993; Priest 1993), the mean fracture trace length for all trace maps is $1.7 \mathrm{~m}$. However, horizontal exposures reveal that systematic joints have straight traces and are more continuous. In general, the joints are censored at the edge of the 


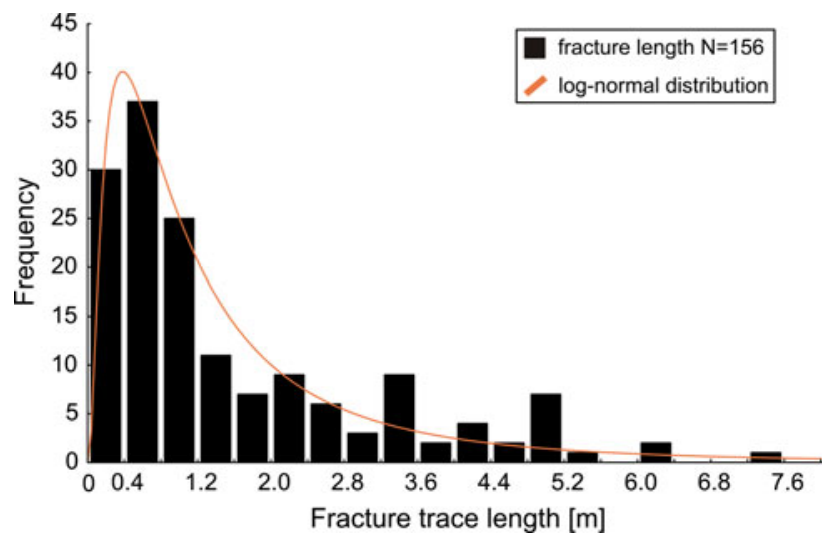

Fig. 5 Distribution of the fracture trace lengths at the Reinhardswald Trough quarry showing a log-normal distribution

observation area and individual measurements suggest that the trace lengths are in the order of several metres. Thus, the data were tested for a power-law distribution (e.g. Bonnet et al. 2001), which generally provides a more detailed description, in particular for large fracture lengths, rather than for those deduced from other classical distributions (Bour and Davy 1997). The evaluation indicates (data not shown) that fitting the trace length to the powerlaw distribution is impossible due to lower truncation (short trace length are inadequately resolved) and censoring (long traces are inadequately sampled). Hence, no power-law distribution or fractal behaviour is observed for the studied fracture length data.

\section{Fracture network generation}

In this study, the field observations indicate a conceptual DFN model that is made of two orthogonal joint sets, which are orientated perpendicular to bedding plane (Fig. 6). An important characteristic of these fracture networks is the different morphology of its two joints sets. This nearly orthogonal joint pattern is the result of two episodes of extension jointing, which involved older systematic joints and younger joints (non-systematic) commonly abutting at right angles to the older (e.g. Hodgson 1961; Bock 1980; Hancock 1985; Mandl 2005). Hedemann (1950) describes that in certain areas of the Reinhardswald Trough, the second fracture set (set II) is hardly ever observed.

Furthermore, it can be shown that the fracture network is largely influenced by lithological layering, since many fractures are mostly confined to single layers. Reasons for fracture arrest are the weakness of the interface or the stiffness contrast between layers (e.g. Pollard and Aydin 1988; Helgeson and Aydin 1991; Cooke and Underwood 2001). Once again, however, there is a difference between both joint sets. Fractures of set I can be more continuous

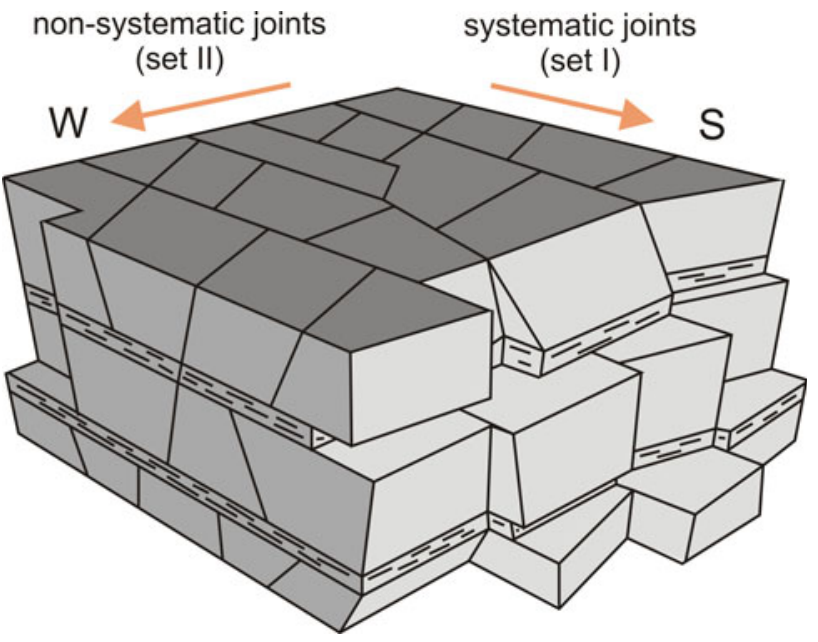

Fig. 6 Conceptual model of the discrete fracture network made up of two nearly orthogonal joint sets that are orientated vertical to bedding plane

and frequently penetrate many layers, whereas those of the other set are mostly confined to single layers. Odling et al. (1999) suggest a classification of fracture systems that describes its behaviour at bedding interfaces. Two endmembers, stratabound and non-stratabound are defined. All stages between these two end-members can be observed and their behaviour at bedding interfaces might also switch at different scales (Odling et al. 1999). Since field observations show that joints are mostly confined to single beds and their spacing tends to be regular, a stratabound DFN system was assumed for the investigated sites.

Discrete fracture network (DFN) models were generated using statistical-derived fracture input data and the distinct element code UDEC for the fracture network generation (Itasca 2006). The detailed description of the fracture system by special parameters shows regional distinctions in the DFN. However, reliable and comprehensive fracture parameters could only be obtained in the centre of the Reinhardswald Trough. Hence, the development of a fracture model was exemplarily carried out for this site, which may be similar to a currently planned geothermal reservoir close to Hannover, to the north of the current site (Kehrer et al. 2007).

The stratabound system implies a unique fracture system in each layer, independent of that in the neighbouring layer. The generation of DFN by special fracture parameters has to be individually completed for each layer (e.g. relationship between joint spacing and bed thickness). Therefore, only one layer of a thickness of $0.55 \mathrm{~m}$ was considered in the current study.

The mean and standard deviation for fracture orientation was determined from strike measurements for each fracture set (Fig. 3). The slope of the best-fit line on a plot of bed thickness versus median joint spacing was used to calculate 
the joint spacing for the specified layer of $0.55 \mathrm{~m}$ thickness for each fracture set (Fig. 4). Due to the linear relationship between fracture spacing and bed thickness, values of the independent variable (in this case joint spacing) could also be used to calculate the standard deviation as a measure of dispersion.

The fracture length of cross joints (set II) is given by the intervening distance between the systematic joints. However, there is no reliable information on the fracture length of the systematic joints (set I) due to lower truncation and censoring effects. Hence, in the present study the mean fracture length from Pahl's method was used (Pahl 1981). In order to enable the generation of systematic joints, which are more continuous as observed in the field (Fig. 7), the gap parameter for the fracture network generation in UDEC was manually adjusted. A summary of the input parameters is given in Table 1.

Even though field measurements of outcrop reservoir analogues provide a detailed description of the fracture system, many uncertainties were identified in this data analysis. The main uncertainty was the result of an incomplete data analysis. While fracture orientation and facture spacing could be measured adequately, the evaluation of fracture lengths turned out to be more complicated. Hence, only incomplete statistical fracture length data were available for the fracture network generation mainly due to the sampling bias. Thus, the validation of the fracture network generation using UDEC was carried out by visual comparison between the generated and observed DFN patterns (Fig. 7). Even though the analysis of joint parameters revealed many uncertainties, the detailed description of the fracture system by field observation and special parameters allowed the generation of very realistic discrete fracture networks.

\section{Hydraulic modelling and REV analysis}

The average equivalent conductivity tensors were analysed with increasing block size to determine the REV of the fractured sandstones. In order to determine the average conductivity tensor for every block size, 50 DFNs were simulated and the three components of the conductivity tensor were calculated. The cumulative average and the cumulative variance of the fitted conductivity tensors were used as an indicator of convergence (Blum et al. 2007). The variance after 15 realisations is less than $1 \%$ of the average for all three components (Fig. 8). Hence, 15 simulations were considered sufficient for the determination of the average conductivity tensor for all block sizes.

In general, the REV of a fractured rock mass is defined as the equivalent block scale at which an equivalent porous media (EPM) can be used to upscale the hydraulic
Fig. 7 Example of a a naturally observed fracture pattern and b a fracture network generated using UDEC

Table 1 Statistical-derived fracture input data for fracture network generation with UDEC (a)

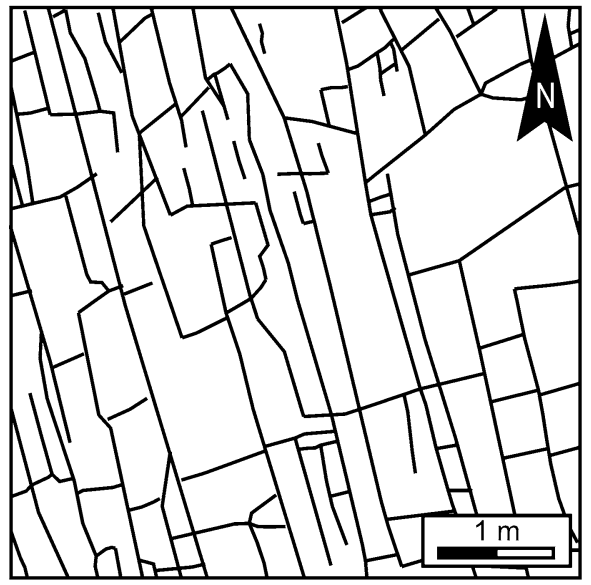

(b)

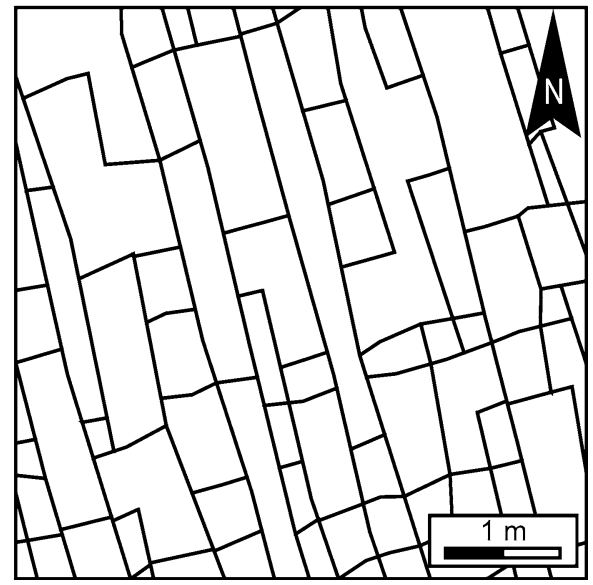

\begin{tabular}{llllll}
\hline & \multicolumn{2}{l}{ Systematic joints } & & \multicolumn{2}{l}{ Cross joints } \\
\cline { 2 - 3 } \cline { 5 - 6 } & Mean & Standard deviation & & Mean & Standard deviation \\
\hline Fracture orientation & $105^{\circ}$ & $6^{\circ}$ & & $16^{\circ}$ & $10^{\circ}$ \\
Joint spacing & $39 \mathrm{~cm}$ & $19 \mathrm{~cm}$ & & $54 \mathrm{~cm}$ & $31 \mathrm{~cm}$ \\
Fracture trace length & $168 \mathrm{~cm}$ & $62 \mathrm{~cm}$ & & $39 \mathrm{~cm}$ & $19 \mathrm{~cm}$ \\
Gap length & - & - & & $10 \mathrm{~cm}$ & - \\
\hline
\end{tabular}


(a)

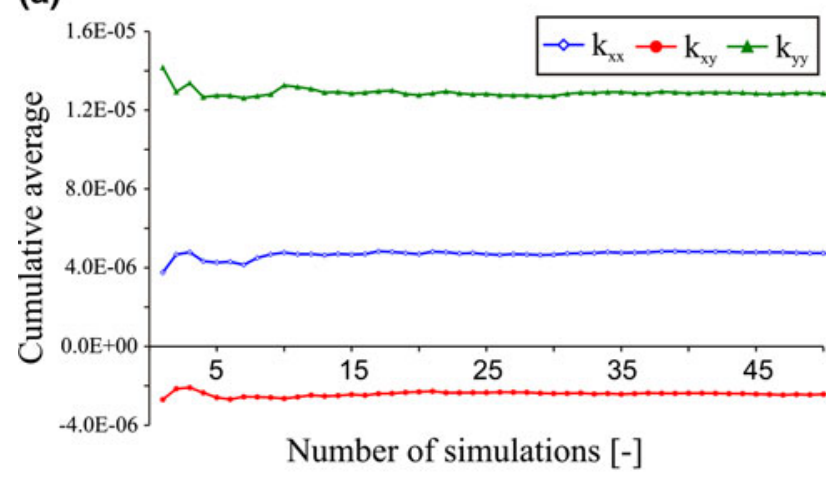

(b)

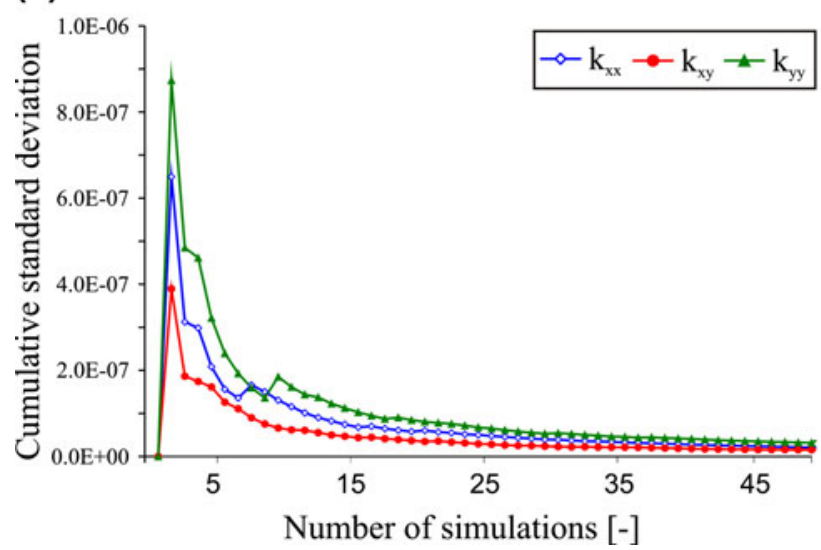

Fig. 8 Cumulative average (a) and cumulative variance (b) of the fitted conductivity tensor for generated networks with a block size of $5 \times 5 \mathrm{~m}$

behaviour of the fractured rock mass. This definition is imprecise, thus in the current study an REV criteria was chosen that was based upon minimisation of the variance of the upscaled property values. Hence, the sampled standard deviation of the principal conductivity components and the principal directions must be less than $1 \%$ of their sampled averages, before the domain size used for their calculation can be defined as above or at the size of the REV. The smallest domain size complying with these criteria is the minimum REV size. Figure 9 illustrates the components of the conductivity tensor and the principal conductivity tensors for the generated DFN with increasing block size from $5 \times 5 \mathrm{~m}$ to $40 \times 40 \mathrm{~m}$. The latter indicates that the conductivity ratios and principal directions are consistent and show only minor deviations. Due to heterogeneity of the fracture sets, the dominant fracture set (systematic joints) mainly controls the principal direction. The application of the described REV criteria showed that the representative block size, i.e. representative elementary volume (REV), was achieved at a domain size of $10 \times 10 \mathrm{~m}$.

Since joints resemble a ladder-like pattern due to regular joint spacing in each direction hydraulic simulations show (a)

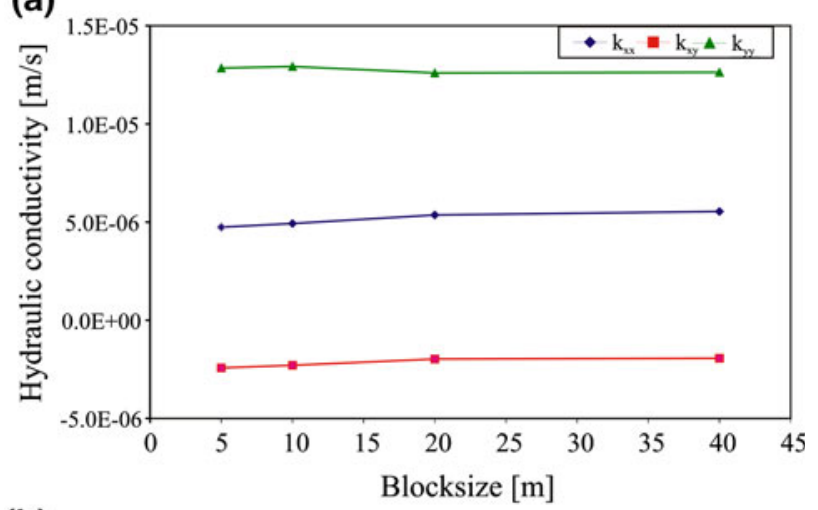

(b)

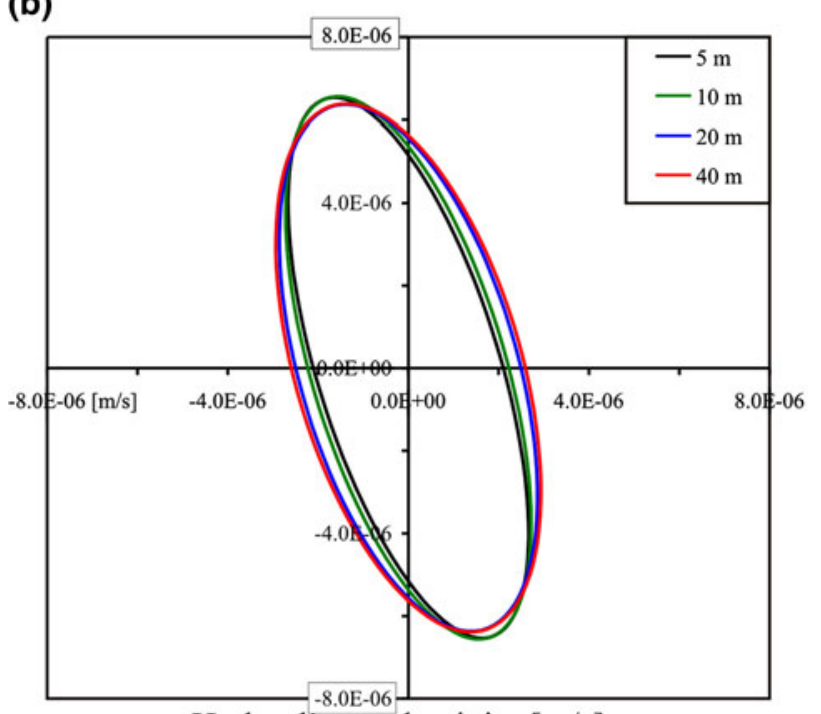

Hydraulic conductivity $[\mathrm{m} / \mathrm{s}]$

Fig. 9 Illustration of a the components of the conductivity tensor and b the principal conductivity tensor with increasing block size

that the joints are horizontally well connected. However, DFN models were generated, which represent statisticalderived fracture data of a definite layer with a given thickness of $0.55 \mathrm{~m}$. The investigated rocks of the Middle Buntsandstein are typically composed of stacks of layers with different thicknesses. Therefore, their hydraulic properties may vary from layer to layer, since each layer has its own distinctive fracture system. Odling et al. (1999) made the assumption that in well-connected fracture systems with orthogonally oriented joints, the REV can be expected at one or two orders of magnitude greater than fracture spacing. This assumption agrees well with the simulated fracture system and the determined REV. Thus, for other layers or investigated sites, the REV must be larger according to layer thickness and fracture spacing. However, in locations where one fracture set was secondarily developed, this assumption must be taken with caution, since the connectivity is reduced and, therefore, will result in a larger REV. 


\section{Conclusions}

The main objective of this study was the evaluation of the representative elementary volume (REV) in fractured sandstones in North Germany using the approach of discrete fracture network (DFN) models. Field measurements of outcrop reservoir analogues were conducted and various realistic stochastic DFN could be generated using statistical-derived fracture input data (fracture orientation, spacing and length) and the universal distinct element code UDEC. An important characteristic of these discrete fracture networks is the different morphology of its two joints sets. Hence, fracture parameters should be collected and analysed to yield specific fracture set information. Furthermore, it can be shown that the DFN is largely influenced by lithological layering. Thus, the fracture spacing was obtained for individual beds with different thicknesses. However, during data analysis many uncertainties were identified. In particular, the evaluation of fracture lengths turned out to be rather difficult mainly due to inevitable sampling bias, i.e. the scale of observation was not large enough to sample larger fracture lengths, which control the connectivity and permeability of the fractured system. Thus, future field studies are necessary to better understand the scaling of fracture lengths in the studied potential geothermal reservoir. Since fracture parameters were conducted from outcrop reservoir analogues, a possible correlation between rocks exposed at the surface and in the reservoir should be scrutinised. Data collected from core and borehole images can provide additional information to correlate fracture parameters from deep wells and outcrops.

Hydraulic simulations of the studied and generated DFNs show that the studied DFN is well connected. Since the fracture systems are made of two orthogonal fracture sets with different fracture properties, the principal direction of fracture flow is mainly controlled by the dominant systematic joints. Thus, for the studied site and the investigated specific layer a representative block size of $10 \times 10 \mathrm{~m}$ could be identified. 2D hydraulic simulations were conducted, which provide information on the fluid flow in the joints that are oriented vertical to bedding plane. Thus, there is no information about fluid flow in the subhorizontal fractures, e.g. the bedding plane. However, obtaining information on the fluid flow along the bedding plane is associated with uncertainty since the sandstones are not constant in thickness and thinned out due to their fluvial architecture. Fluid flow in the DFN is, therefore, controlled by the lateral extent of individual beds. Furthermore, sandstones are intercalated with silt- or claystones that lead to low permeable bedding plane fractures.

A constant hydraulic aperture was used for the hydraulic simulations. However, the permeability of a fractured reservoir in the subsurface is not only a function of the geometry of the fracture system, but also depends on the stress state of the reservoir. The latter would result in heterogeneously distributed hydraulic apertures. Thus, further studies should be performed to study the hydromechanical behaviour of the fractured geothermal reservoir with increasing in situ and effective stresses, for example, by using the empirical mechanical Barton-Bandis (BB) model.

Acknowledgments The project is sponsored by the scholarship programme of the German Federal Environmental Foundation (Deutsche Bundesstiftung Umwelt, DBU). Furthermore, we would like to thank Stefan Hoffmann for his help in collecting the fracture data from outcrop studies.

Open Access This article is distributed under the terms of the Creative Commons Attribution Noncommercial License which permits any noncommercial use, distribution, and reproduction in any medium, provided the original author(s) and source are credited.

\section{References}

Adler P, Thovert J (1999) Fractures and fracture networks. Kluwer Academic Publishers, Dordrecht

Bachmann G (1998) The Germanic Triassic: general. Hallesches Jahrb Geowiss Reihe B(6):19-22

Baecher G, Lanney N, Einstein H (1977) Statistical description of rock properties and sampling. In: Proceedings of the 18th US symposium on rock mechanics, Colorado School of Mines Press, Colorado

Baghbanan A, Jing L (2007) Hydraulic properties of fractured rock masses with correlated fracture length and aperture. Int J Rock Mech Min Sci 44(5):704-719

Bai T, Pollard D (2000) Fracture spacing in layered rocks: a new explanation based on the stress transition. J Struct Geol 22(1):43-57

Bear J (1972) Dynamics of fluids in porous media. Environmental science series. Elsevier, Amsterdam, p 784

Berkowitz B (2002) Characterizing flow and transport in fractured geological media: a review. Adv Water Resour 25(8-12):861-884

Bertani R (2005) World geothermal power generation in the period 2001-2005. Geothermics 34:651-690

Bindig M (1991) Räumliche und zeitliche Entwicklung der Fluviatilen Environments der Solling-formation (Buntsandstein, Germanische Trias). PhD thesis, Technical University of Darmstadt

Blum P, Mackay R, Riley M, Knight J (2005) Performance assessment of a nuclear waste repository: upscaling coupled hydro-mechanical properties for far-field transport analysis. Int $\mathbf{J}$ Rock Mech Min Sci 42(5-6):781-792

Blum P, Mackay R, Riley M, Knight J (2007) Hydraulische Modellierung und die Ermittlung des repräsentativen Elementarvolumens (REV) im Kluftgestein. Grundwasser 12(1):48-65

Blum P, Mackay R, Riley M (2009) Stochastic simulations of regional scale advective transport in fractured rock masses using block upscaled hydro-mechanical rock property data. J Hydrol 369:318-325

Bock H (1980) Das Fundamentale Kluftsystem. Z dt geol Ges 131:627-650

Bonnet E, Bour O, Odling N, Davy P, Main I, Cowie P, Berkowitz B (2001) Scaling of fracture systems in geological media. Rev Geophys 39(3):347-383 
Bour O, Davy P (1997) Connectivity of random fault networks following a power law fault length distribution. Water Resour Res 33(7):1567-1583

Brown S (1987) Fluid flow through rock joints: the effect of surface roughness. J Geophys Res 92(B2):1337-1347

Cloos H (1936) Einführung in die Geologie [An introduction to geology]. Bornträger, Berlin

Cooke M, Underwood C (2001) Fracture termination and step-over at bedding interfaces due to frictional slip and interface opening. J Struct Geol 23(2-3):223-238

Dietrich P, Helmig R, Sauter M, Hötzl H, Köngeter J, Teutsch G (2005) Flow and transport in fractured porous media. Springer, Berlin

GDNRW (2003) Geologie im Weser- und Osnabrücker Bergland [Geology of the Weser river region], Geologischer Dienst NRW [Geology survey North Rhine-Westphalia]

Grobler H, Poropat G, Guest A (2003) Photogrammetry for structural mapping in mining. In: Handley M, Stacey D (eds) Proceedings of the 10th congress of the international society for rock mechanics, Sandton (Johannesburg), The South African Institute of Mining and Metallurgy, Johannesburg, pp 431-436

Gross M (1993) The origin and spacing of cross joints: examples from the Monterey Formation, Santa Barbara Coastline, California. J Struct Geol 15(6):737-751

Gross M, Fischer M, Engelder T, Greenfield R (1995) Factors controlling joint spacing in interbedded sedimentary rocks: integrating numerical models with field observations from the Monterey Formation, USA. Geol Soc London Spec Publ 92(1):215-233

Hancock P (1985) Brittle microtectonics: principles and practice. J Struct Geol 7(3/4):437-457

Hedemann, HA (1950) Entwicklung und Struktur des Sollinggewölbes. $\mathrm{PhD}$ thesis, Technical University of Clausthal Zellerfeld

Helgeson D, Aydin A (1991) Characteristics of joint propagation across layer interfaces in sedimentary rocks. J Struct Geol 13(8):897-911

Hitchmough A, Riley M, Herbert A, Tellam J (2007) Estimating the hydraulic properties of the fracture network in a sandstone aquifer. J Contam Hydrol 93(1-4):38-57

Hodgson R (1961) Classification of structures on joint surfaces. Am J Sci 259(7):493-502

Huang Q, Angelier J (1989) Fracture spacing and its relation to bed thickness. Geol Mag 126(4):355-362

Itasca (2006) UDEC-Universal Distinct Element Code-User's Guide. Itasca Consulting Group Inc, Minneapolis

Jackson C, Hoch A, Todman S (2000) Self-consistency of a heterogeneous continuum porous medium representation of a fractured medium. Water Resour Res 36(1):189-202

Ji S, Saruwatari K (1998) A revised model for the relationship between joint spacing and layer thickness. J Struct Geol 20(11):1495-1508

Jing L (2003) A review of techniques, advances and outstanding issues in numerical modelling for rock mechanics and rock engineering. Int J Rock Mech Min Sci 40(3):283-353

Jung R (2007) Stand und Aussichten der Tiefengeothermie in Deutschland. Erdöl Erdgas Kohle 123(2):1-7

Kehrer P, Orzol J, Jung R, Jatho R, Junker R (2007) The GeneSys project a contribution of GEOZENTRUM Hannover to the development of Enhanced Geothermal Systems (EGS). Z dt geol Ges 158:119-132

Khaleel R (1989) Scale dependence of continuum models for fractured basalts. Water Resour Res 25(8):1847-1855

Kohl T, Megel T (2007) Predicitve modeling of reservoir response to hydraulic stimulations at the European EGS Site Soulz-sousForets. Int J Rock Mech Min Sci 44(8):1118-1131

Kolditz O (1995a) Modelling of flow and heat transfer in fractured rock: conceptual model of a 3-D deterministic fracture network. Geothermics 24(3):451-470
Kolditz O (1995b) Modelling of flow and heat transfer in fractured rock: dimensional effect of matrix heat diffusion. Geothermics 24(3):421-438

Kulatilake P, Panda B (2000) Effect of block size and joint geometry on jointed rock hydraulics and REV. J Eng Mech 126:850-858

Kulatilake P, Wu T (1984) Estimation of mean trace length of discontinuities. Rock Mech Rock Eng 17(4):215-232

Ladeira F, Price N (1981) Relationship between fracture spacing and bed thickness. J Struct Geol 3(2):179-183

Lee C, Farmer I (1993) Fluid flow in discontinuous rocks. Chapman and Hall, New York

Lee C, Deng B, Chang J (1995) A continuum approach for estimating permeability in naturally fractured rocks. Eng Geol 39(1-2): $71-85$

Lee C, Lee C, Lin B (2007) The estimation of dispersion behavior in discrete fractured networks of andesite in Lan-Yu Island, Taiwan. Env Geol 52(7):1297-1306

Lepper J, Röhling H (1998) Buntsandstein. Hallesches Jahrb Geowiss Reihe B(6):27-34

Long J (1983) Investigation of equivalent porous medium permeability in networks of discontinuous fractures. $\mathrm{PhD}$ thesis, University of California, Berkeley

Long J, Remer J, Wilson C, Witherspoon P (1982) Porous media equivalents for networks of discontinuous fractures. Water Resour Res 18(3):645-658

Mandl G (2005) Rock joints: the mechanical genesis. Springer, Berlin

Mauldon M (1998) Estimating mean fracture trace length and density from observations in convex windows. Rock Mech Rock Eng 31(4):201-216

Min K, Jing L, Stephansson O (2004) Determining the equivalent permeability tensor for fractured rock masses using a stochastic REV approach: method and application to the field data from Sellafield, UK. Hydrogeol J 12(5):49-510

Moreno L, Tsang Y, Tsang C, Hale F, Neretnieks I (1988) Flow and tracer transport in a single fracture: a stochastic model and its relation to some field observations. Water Resour Res 24(12): 2033-2048

Narr W (1996) Estimating average fracture spacing in subsurface rock. AAPG Bull 80(10):1565-1586

Narr W, Suppe J (1991) Joint spacing in sedimentary rocks. J Struct Geol 13(9):1037-1048

Neuman SP (1987) Stochastic continuum representation of fractured rock permeability as an alternative to the REV and fracture network. In: Proceedings of the 28th US symposium on rock mechanics, Tuscon, 29 June-1 July 1987, pp 533-561

Nirex (1997) Evaluation of heterogeneity and scaling of fractures in the Borrowdale Volcanic Group in the Sellafield area. Nirex Report SA/97/028, Harwell, UK

Odling N, Gillespie P, Bourgine B, Castaing C, Childs J, Christensen N, Fillion E, Gender A, Olsen C, Thrane L, others (1999) Variations in fracture system geometry and their implications for fluid flow in fractured hydrocarbon reservoirs. Petroleum Geosci 5:373-384

Pahl P (1981) Estimating the mean length of discontinuity traces. Int J Rock Mech Min Sci Geomech Abstr 18(3):221-228

Panda B, Kulatilake P (1999) Effect of joint geometry and transmissivity on jointed rock hydraulics. J Eng Mech 125(1):41-50

Pickering G, Bull J, Sanderson D (1995) Sampling power-law distributions. Tectonophysics 248(1-2):1-20

Pollard D, Aydin A (1988) Progress in understanding jointing over the past century. Bull Geol Soc Am 100(8):1181-1204

Priest S (1993) Discontinuity analysis for rock engineering. Springer, Berlin

Priest S, Hudson J (1981) Estimation of discontinuity spacing and trace length using scanline. Int J Rock Mech Min Sci Geomech Abstr 18:183-197 
Priest S, Samaniego J (1983) A model for the analysis of discontinuity characteristics in two dimensions. In: Proceedings of the 5th ISRM congress, Melbourne, pp 199-207

Renshaw C (1995) On the relationship between mechanical and hydraulic apertures in rough-walled fractures. J Geophys Res 100(B12):24629-24636

Rettig B (1996) Die Solling-Folge (Mittlerer Buntsandstein) im Grenzgebiet: Niedersachsen, Thüringen, Hessen, Mitteilungen aus dem Geologischen Insitut der Universität Hannover 35

Sahimi M (1995) Flow and transport in porous media and fractured rock: from classical methods to modern approaches. $\mathrm{VCH}$, Weinheim, NewYork

Shapiro AM, Andersson J (1983) Steady state fluid response in fractured rock: a boundary element solution for a coupled, discrete fracture continuum model. Water Resour Res 19:959969

Snow D (1965) A parallel plate model of fractured permeable media. $\mathrm{PhD}$ thesis, University of California, Berkeley

Song J, Lee C (2001) Estimation of joint length distribution using window sampling. Int J Rock Mech Min Sci 38(4):519-528

Steele A, Reynolds DA, Kueper BH, Lerner DN (2006) Field determination of mechanical aperture, entry pressure and relative permeability of fractures using NAPL injection. Geotechnique $56(1): 27-38$
Terzaghi R (1965) Sources of error in joint surveys. Geotechnique 15(3):287-304

Thompson M, Brown S (1991) The effect of anisotropic surface roughness on flow and transport in fractures. J Geophys Res 96(B13):21923-21932

Wathugala D, Kulatilake P, Wathugala G, Stephansson O (1990) A general procedure to correct sampling bias on joint orientation using a vector approach. Comput Geotech 10:1-31

Weber J, Ricken W (2005) Quartz cementation and related sedimentary architecture of the Triassic Solling Formation, Reinhardswald Basin, Germany. Sed Geol 175(1-4):459-477

Witherspoon P, Wang J, Iwai K, Gale J (1980) Validity of cubic law for fluid flow in a deformable rock fracture. Water Resour Res 16(6):1016-1024

Wu H, Pollard D (1995) An experimental study of the relationship between joint spacing and layer thickness. J Struct Geol 17(6):887-905

Wu H, Pollard D (2002) Imaging 3-D fracture networks around boreholes. AAPG Bull 86(4):593-604

Zhang L, Einstein H (1998) Estimating the mean trace length of rock discontinuities. Rock Mech Rock Eng 31(4):217-235

Zhang X, Sanderson D (2002) Numerical modelling and analysis of fluid flow and deformation of fractured rock masses. Pergamon, Boston 